\title{
Note
}

\section{The Timing of Egg-laying in Macrobiotid Species (Tardigrada) on the Island of Newfoundland}

\author{
Kyla K. Brake ${ }^{1}$ and Michael A. J. COLlins ${ }^{2,3}$ \\ ${ }^{1}$ Department of Environment and Conservation, Government of Newfoundland and Labrador, St. John's, Newfoundland and \\ Labrador A1B 4J6 Canada \\ ${ }^{2}$ Department of Biology, Memorial University, St. John's, Newfoundland and Labrador A1B 3X9 Canada \\ ${ }^{3}$ Corresponding author: collinsm@mun.ca
}

Brake, Kyla K., and Michael A. J. Collins. 2016. The timing of egg-laying in macrobiotid species (Tardigrada) on the island of Newfoundland. Canadian Field-Naturalist 130(1): 34-37.

Previous sampling of lichens and mosses on the island of Newfoundland has not located any macrobiotid (family Macrobiotidae) eggs, which are often crucial to the positive identification of adults of this family, particularly Macrobiotus and Minibiotus species. Because recent studies have established that egg-laying in macrobiotid species in the more northerly Labrador part of the province occurs in late summer and early fall, it was hypothesized that egg-laying on the more southerly island of Newfoundland would take place later in the year. In this study, conducted on the Burin Peninsula from September to December 2005, moss samples were taken every 2 weeks and macrobiotid adults and eggs were extracted. The eggs of 3 species of Macrobiotus and 1 species of Minibiotus were recovered later in the fall after the first frost.

Key Words: Tardigrada; Macrobiotus; Minibiotus; egg-laying; Newfoundland

\section{Introduction}

Freshwater and semi-terrestrial tardigrades produce several eggs at a time, which are either smooth and are shed in the old exuvium during a moult or are intricately ornamented and are laid freely in the environment, singly, in pairs, or in groups. Smooth eggs are produced by species of both heterotardigrades and eutardigrades, whereas ornamented eggs are produced only by the latter (Kinchin 1994). Egg shell ornamentation varies and allows one to distinguish between species, particularly within the genera Macrobiotus C.A.S. Schultze, 1834 and Minibiotus Schuster, 1980 where the adults quite often closely resemble one another. Although the evolutionary benefit of ornamented eggs is unclear, Ramazzotti and Maucci (1983) have proposed that the processes keep eggs from being swept away by external agents, such as wind and water.

Little is known about the timing of egg-laying in tardigrades. Ramazzotti and Maucci (1983) state that eggs can be found at any time of year in mosses, lichens, and soil, and Pennak (1953) generalizes the peak of reproductive activity between November and May. Nelson (1982) has found that eggs appear to be more numerous during the winter in soil-inhabiting species. Kristensen (1980) has reported finding the largest number of eggs in Greenland samples during mid-winter months. In Tennessee, Kendall-Fite (1993) found the eggs of Minibiotus intermedius Plate, 1888 most often during December, whereas Nichols (1999), working further south in Alabama, found few eggs and mostly in January and April. In the United Kingdom, Morgan and King (1976) state that eggs, whether associated with an exuvium or deposited freely, can be found there in small numbers throughout the year. However, they also suggest that, depending on climatic conditions, egglaying may occur in small peaks throughout the year, including one in January.

In a preliminary survey of the tardigrades of the island of Newfoundland, very few eggs were found in moss and lichen samples, and no macrobiotid eggs were found (Bateman and Collins 2001). However, a more recent investigation of tardigrades in Labrador, the mainland portion of the province of Newfoundland and Labrador, yielded interesting results (Boeckner et al. 2006). During a preliminary survey in October 2001, no eggs were found. However, in 2002, 1 egg was located in the June samples, and 35 eggs were found 2 months later in August. Because the climate of the northeast coast of Labrador is cooler than that of the island it was surmised that egg-laying on Newfoundland occurred later in the year than in Labrador. The temperatures during August in Labrador correspond more closely with those found in early October on the island (Environment Canada 2011). The most probable explanation, then, for the lack of eggs in the previous Newfoundland study (Bateman and Collins 2001) might be the time of sampling (between June and August), which was too early to collect eggs laid later, in the fall.

Species of the genera Macrobiotus and Minibiotus can be positively identified only through the concurrent collection of eggs and adult specimens at the same location (Kinchin 1994). A number of Macrobiotus species, including M. harmsworthi J. Murray, 1907, and M. cf. hufelandi C.A.S. Schultze, 1833, as well as Minibiotus intermedius, were tentatively identified earlier on Newfoundland (Bateman and Collins 2001), but as no eggs 
were collected together with the adults, no definite identifications could be made.

The primary purpose of this study was to determine when macrobiotid reproduction and egg-laying occurs on the island of Newfoundland. This will enable positive identification of Macrobiotus and Minibiotus species based on availability of both adults and eggs.

\section{Methods}

Preliminary sampling of potential study areas in the vicinity of Marystown $\left(47^{\circ} 10^{\prime} \mathrm{N}, 55^{\circ} 10^{\prime} \mathrm{W}\right)$ on the Burin Peninsula, Newfoundland, was conducted in early September 2005 to determine which sites contained tardigrades. Of the 11 sites selected, 10 contained tardigrades. These sites were then sampled at 2-week intervals for 4 months (September to December). Because the main purpose of the study was to find out if and when egg-laying was taking place, no attempts were made to take multiple samples at each site, but rather to take a single sample from as many sites as possible to enhance the chance of locating eggs.

Each sample, consisting of approximately $200 \mathrm{~g}$ of moss, was stored in a labeled brown paper lunch-style bag and allowed to dry out naturally. A volume of $14 \mathrm{~cm}^{3}$ of each dried moss sample was soaked in separate plastic Petri dishes in tap water for $18-24 \mathrm{~h}$ to activate the cryptobiosing tardigrades and then attempt to induce anoxybiosis, causing the tardigrades to release their hold on the moss and collect in the water from which they can be easily removed (Romano 2003). After stirring and squeezing the moss sample to remove any tardigrades not already suspended in the water, the samples were soaked in tap water again and squeezed thoroughly a second time to ensure maximum recovery of tardigrade adults and eggs. Both active and inactive tardigrades, as well as eggs and exuvia, were removed from the dish by hand using a glass pipette. Each adult tardigrade and each egg was mounted in Hoyer's medium (Kinchin 1994) on a microscope slide, covered with a coverslip, and dried on a slide dryer for a week.
Identification of the specimens was based primarily on the work of Ramazzotti and Maucci (1983) with additional information on individual species from Bertolani and Rebecchi (1993), Kathman (1989, 1990), and Kathman and Cross (1991). The microscope slides containing the adults and eggs (K2005: numbers 001415) are held in the Biology Department, Memorial University.

\section{Results}

Based on descriptions and diagrams in Argue (1971, 1972, 1974), Morgan and King (1976), Ramazzotti and Maucci (1983), Kathman (1989, 1990), Bertolani and Rebecchi (1993), and Kinchin (1994), 4 types of eggs were recovered and identified as belonging to Macrobiotus crenulatus, $M$. harmsworthi, $M$. cf. hufelandi, and Minibiotus cf. intermedius. Only 4 of the 10 sample sites yielded eggs during this period; thus, only collections from these 4 sites are reported (Table 1).

Single eggs of Macrobiotus cf. hufelandi, M. harmsworthi, and M. crenulatus were obtained in September and October, but most eggs were found from midOctober onward. The specific periods during which eggs were located for each of the 4 macrobiotid species in this study were: M. crenulatus, mid-September to early December; $M$. cf. hufelandi, early September to early December; $M$. harmsworthi, October to late December; Minibiotus cf. intermedius, late November to December (sampling ended in late December).

\section{Discussion}

The results of this limited study suggest that egglaying by Macrobiotus $\mathrm{cf}$. hufelandi, M. harmsworthi, M. crenulatus, and Minibiotus cf. intermedius on the Burin Peninsula, Newfoundland, takes place in the fall. It appears then, that concurrent collection of eggs and adults of these 4 species in areas with a climate similar to that of Newfoundland could be achieved by sampling in late fall. This is not to say that egg-laying might not also take place at other times of the year, perhaps dur-

TABLE 1. Number of eggs of 4 macrobiotid species found from September to December 2005 on the Burin Peninsula, Newfoundland.

\begin{tabular}{lccccc}
\hline \hline & \multicolumn{2}{c}{ Species } & & \\
Date & \multicolumn{1}{c}{$\begin{array}{c}\text { Macrobiotus } \\
\text { crenulatus }\end{array}$} & $\begin{array}{c}\text { Macrobiotus } \\
\text { cf. hufelandi }\end{array}$ & $\begin{array}{c}\text { Minibiotus } \\
\text { cf. intermedius }\end{array}$ & $\begin{array}{c}\text { All } \\
\text { species }\end{array}$ \\
\hline 2 Sept. & 0 & 0 & 1 & 0 & 1 \\
17 Sept. & 1 & 0 & 0 & 0 & 1 \\
1 Oct. & 1 & 1 & 1 & 0 & 3 \\
15 Oct. & 11 & 0 & 3 & 0 & 14 \\
29 Oct. & 11 & 0 & 0 & 0 & 11 \\
13 Nov. & 19 & 0 & 0 & 2 & 19 \\
26 Nov. & 19 & 0 & 0 & 2 & 32 \\
11 Dec. & 4 & 0 & 11 & 1 & 8 \\
24 Dec. & 0 & 9 & 0 & 5 & 10 \\
Total & 66 & 10 & & 0 & 99 \\
\hline \hline
\end{tabular}


ing winter or spring; however, no sampling was attempted at these times. It is unlikely that egg-laying takes place during the summer months, as previous collecting during many summers has yielded no eggs. Morgan and King (1976) have found that (in the United Kingdom) fertilized eggs hatch in 1-10 days, depending on climatic conditions. It seems likely, therefore, that tardigrade eggs do not persist in the environment for long periods; thus, even if eggs were laid early in the year, they would not be found during the summer.

The number of sampling sites was relatively small in this limited study $(n=11)$. Authors such as Degma et al. (2011: 71) state that

Because of the patchiness of Tardigrada populations (e.g., Meyer 2006; Jönsson 2007), a large number of replicate samples is necessary for obtaining valid data for ecological studies (e.g., Nelson 2002). The required number of samples per treatment (value of environmental variable) can be very high (from a few hundred to more than 1000) to reduce the standard error of the population estimates. This fact makes ecological studies of tardigrade populations and communities very difficult, and few, if any, studies have had sufficient sample sizes.

Our study, then, in common with most studies of tardigrades in natural settings, also suffers from limited sampling. Future such studies should, therefore, involve many more sampling sites and individual samples, although Degma (2010) has stated that it is possible to take qualitative samples if the researcher is interested only in species richness.

The current study was limited to samples of moss and cannot necessarily be generalized to egg-laying in other substrates, such as lichens, liverworts, leaf litter, and soil. As Meyer (2013) has pointed out, most terrestrial sampling in the Americas has focused on cryptogams, with $90 \%$ collected from such substrates compared with $14 \%$ from leaf litter, $20 \%$ from soil, and $24 \%$ in aquatic samples. Future studies of egg-laying should, therefore, include samples from other cryptogams (lichens and liverworts), leaf litter, and soil to see if the timing of egg-laying on these substrates is similar to that for mosses.

It would also be instructive to conduct a year-round sampling study to see if egg-laying takes place at other times of year, particularly January through May, as has been found in other locations (e.g., Pennak 1953; Morgan and King 1976; Kristensen 1980; Nichols 1999).

\section{Acknowledgements}

We thank Mr. Nigel Marley (University of Plymouth, UK) for assistance in the identification of $M$. crenulatus, and Mr. Roy Ficken for his assistance with the research microscope. We also thank Professor Lois Bateman for her helpful comments on this manuscript.

\section{Literature Cited}

Argue, C. W. 1971. Some terrestrial tardigrades from New Brunswick, Canada. Canadian Journal of Zoology 49: 401-415.
Argue, C. W. 1972. Tardigrades from New Brunswick, Canada. 2. Canadian Journal of Zoology 50: 87-94.

Argue, C. W. 1974. Tardigrades from New Brunswick, Canada. 3. Canadian Journal of Zoology 52: 919-922.

Bateman, L., and M. Collins. 2001. A preliminary account of the Tardigrades of Newfoundland. Zoologischer Anzeiger 240: 223-232.

Bertolani, R., and L. Rebecchi. 1993. A revision of the Macrobiotus hufelandi group (Tardigrada, Macrobiotidae), with some observations on the taxonomic characters of eutardigrades. Zoologica Scripta 22: 127-152.

Boeckner, M., M. Collins, J. Finney-Crawley, and L. Bateman. 2006. The bryofauna of remote coastal Labrador: including a review of current Canadian records. Zootaxa 1105: 1-16.

Degma, P. 2010. Moss dwelling Tardigrada — from sampling to their identification. European Distributed Institute of Taxonomy, Summer School 2010, Madeira, Spain.

Degma, P., Katina, S., and L. Sabatovičovà. 2011. Horizontal distribution of moisture and Tardigrada in a single moss cushion. Journal of Zoological Systematics and Evolutionary Research 49(s1): 71-77.

Environment Canada. 2016. 1981-2010 Canadian climate normals. Environment Canada, Ottawa, Ontario, Canada. Accessed 2 March 2016. http://climate.weather.gc.ca/cli mate_normals/index_e.html.

Jönsson, I. K. 2007. Long-term experimental manipulation of moisture conditions and its impact on moss-living tardigrades. Journal of Limnology 66(1s): 119-125.

Kathman, R. D. 1989. Studies on the Tardigrada of Vancouver Island, British Columbia. Ph.D. thesis, University of Victoria, British Columbia, Canada.

Kathman, R. D. 1990. Eutardigrada from Vancouver Island, British Columbia, Canada, including a description of Platicrista cheleusis n.sp. Canadian Journal of Zoology 68: 1880-1895.

Kathman, R. D., and S. F. Cross. 1991. Ecological distribution of moss-dwelling tardigrades on Vancouver Island, British Columbia, Canada. Canadian Journal of Zoology 69: $122-129$.

Kendall-Fite, K. L. 1993. Tardigrades from Short Mountain, Cannon County, Tennessee. M.Sc. thesis, Middle Tennessee State University, Murfreesboro, Tennessee, USA.

Kinchin, I. M. 1994. The Biology of Tardigrades. Portland Press, London, UK.

Kristensen, R. M. 1980. Zur Biologie des marinen Heterotardigraden Tentrakentron synaptae. Helgolander Meeresunters 34: 165-167.

Meyer, H. A. 2006. Small-scale spatial distribution heterogeneity in terrestrial tardigrade populations. Hydrobiologia 558: 133-139.

Meyer, H. A. 2013. Terrestrial and freshwater Tardigrada of the Americas. Zootaxa 3747: 1-71.

Morgan, C. I., and P. E. King. 1976. British Tardigrades, Tardigrada: Keys and Notes for the Identification of Species. Synopses of the British Fauna (NS) 9. Academic Press, New York, New York, USA.

Nelson, D. R. 1982. Developmental biology of the Tardigrada. Pages 363-368 in Developmental Biology of Freshwater Invertebrates. Edited by F. W. Harrison and R. R. Cowden. Alan R. Liss Inc., New York, New York, USA.

Nelson, D. R. 2002. Current status of the Tardigrada: evolution and ecology. Integrative and Comparative Biology 42: $652-659$. 
Nichols, P. B. 1999. The ecological distribution of the Tardigrada on Dugger Mountain (NE Alabama) with respect to seasonal and altitudinal variation. M.Sc. thesis, Jacksonville State University, Jacksonville, Alabama, USA.

Pennak, R. 1953. Fresh Water Invertebrates of the United States. Ronald Press, New York, New York, USA.
Ramazzotti, G., and W. Maucci. 1983. Il Phylum Tardigrada. Memorie dell' Istituto Italiano di Idrobiologia 41: 1-1012. Romano, F. A. 2003. On water bears. Florida Entomologist 86: $134-137$.

Received 23 October 2013

Accepted 23 December 2015 